\title{
Antropônimos ficcionais em personagens de histórias clássicas infantis traduzidas para Libras
}

\author{
Fictional anthroponyms in characters from classic children's stories \\ translated to Libras
}

\author{
Gabriele Cristine Rech ${ }^{1}$ \\ Fabíola Sucupira Ferreira Sell ${ }^{2}$
}

\begin{abstract}
Resumo: Este trabalho tem por objetivo investigar de que forma os nomes de personagens das obras literárias clássicas infantis são traduzidos da Língua Portuguesa para a Libras, tendo em vista a tradução intermodal de antropônimos ficcionais. Para tanto, parte-se dos estudos antroponomásticos e dos procedimentos de tradução de nomes fantasia da literatura infantil. Como procedimentos metodológicos foram selecionados 16 sinais de nomes traduzidos do português para a Libras de oito histórias clássicas da literatura infantil traduzidas por profissionais do Instituto Nacional de Educação de Surdos (INES) em meados dos anos 2000 e disponíveis no site do instituto. Como resultados, os procedimentos de tradução mais produtivo foi rendition, isoladamente ou em combinação com outros procedimentos. Como conclusões, pode-se evidenciar que tiveram influência nas traduções tanto aspectos ligados às modalidades das línguas envolvidas no processo de tradução, bem como características próprias na nomeação na Libras, evidenciadas por estudos da antroponomástica das línguas de sinais.
\end{abstract}

Palavras-chave: Libras. Antroponomástica Ficcional. Estudos da Tradução. Sinais de Nome na Literatura Infantil.

\begin{abstract}
This work aims to investigate how the names of characters in classic children's literature are translated from Portuguese to Libras, considering the intermodal translation of fictional anthroponyms and anthroponomastic studies and procedures to translate fictitious names in children's literature. As a methodological procedure, 16 name signs translated from Portuguese to Libras were selected from eight classic stories of children's literature translated by INES's Teachers. The results show that the most productive translation procedure was "rendition", alone or in combination with other procedures. As conclusions, aspects related to the modalities of the languages involved in the translation process influenced the translations, as well as the characteristics of the naming in Libras, evidenced by studies of the anthroponomastics of sign languages.
\end{abstract}

Keywords: Libras. Fictional Anthroponomastics. Translation Studies. Sign names in Children's Literature.

\footnotetext{
${ }^{1}$ Universidade Estadual de Mato Grosso do Sul, Dourados, MS; Universidade Estadual do Oeste do Paraná, Programa de Pós-Graduação em Letras, Cascavel, PR, Brasil. Endereço eletrônico: gabriele@ uems.br.

${ }^{2}$ Universidade do Estado de Santa Catarina, Centro de Ciências Tecnológicas, Programa de Pós-Graduação em Ensino de Ciências, Matemática e Tecnologias, Joinville, SC, Brasil. Endereço eletrônico: fabiola.sell@udesc.br.
} 


\section{Considerações iniciais}

Seide (2016) no artigo de revisão de literatura intitulado Métodos de pesquisa em Antroponomástica, demonstra por meio de uma análise de 33 artigos publicados no Anais relativo ao $24^{\circ}$ Encontro do Conselho Internacional de Onomástica - International Council of Onomastics (ICOS), a riqueza dos estudos Antroponomásticos e as inúmeras possibilidades de diálogos com outras ciências como, por exemplo, a História, a Literatura e os Estudos da Tradução. Com relação a estas duas últimas áreas a autora afirma que essas abordagens parecem ser recentes na área e existe uma escassez de investigações.

Embora Seide (2016) não relate os motivos da escassez de trabalhos envolvendo a Antroponomástica e os Estudos da Tradução, parece ser plausível que um dos motivos esteja relacionado a existência do mito da impossibilidade tradutória do nome próprio (SILVA, 2016; NORD, 2003).

As pesquisas mencionadas até o momento envolveram apenas as línguas orais. Em relação às línguas de sinais a escassez de pesquisas envolvendo os Estudos Antroponomásticos em diálogo com os Estudos da Tradução é ainda mais acentuada.

Nesse sentido, este trabalho se propõe a investigar os estudos da antroponímia da Libras com uma interface com as traduções literárias realizadas nesta língua. Sendo assim, pretendese discutir de que forma os nomes de personagens das obras literárias clássicas infantis são traduzidos da Língua Portuguesa para Língua de Sinais, tendo em vista, portanto, a tradução de antropônimos ficcionais.

Para isso, buscou-se nas traduções dos clássicos da literatura infantil para a Libras, disponíveis em vídeos no site do Instituto Nacional de Educação de Surdos (INES), os sinais de nome para os personagens de oito histórias, a saber: Chapeuzinho Vermelho; Patinho Feio; Rapunzel; Cinderela; Branca de Neve e os Sete Anões; João e Maria; A Bela adormecida; e Os Três Ursos ${ }^{3}$.

Neste artigo apresentamos um breve resgate da Onomástica e da Antroponomástica, seguida da contextualização dos Estudos Antroponomásticos na Libras. Na sequência, são apresentados o referencial teórico referente à tradução de nomes fictícios e os procedimentos metodológicos para a escolha das histórias e para a coleta de dados. Por fim discute-se a análise dos dados e são apresentadas as considerações finais.

\footnotetext{
${ }^{3}$ Três Ursos é o nome da história que consta no site do INES, a qual pode ser encontrada em versões semelhantes como Cachinhos Dourados e os três ursos ou apenas Cachinhos Dourados.
} 


\section{Onomástica e Antroponomástica}

A ciência que compreende os estudos dos nomes próprios é denominada Onomástica, a qual constitui-se como uma área de conhecimento autônoma em constante diálogo com outras áreas, como a Linguística, a História, a Antropologia, dentre outras (AMARAL; SEIDE, 2020). Seabra (2006, p. 1953) afirma que "a Onomástica se integra à Lexicologia” uma vez que os nomes de pessoas e nomes de lugares fazem parte do léxico como um todo e segundo a autora “o patrimônio lexical de uma língua constitui um arquivo que armazena e acumula as aquisições culturais representativas de uma sociedade, refletindo percepções e experiências multisseculares de um povo" (SEABRA, 2006, p. 1953).

Como os nomes próprios são uma classe bastante diversa, várias classificações tipológicas foram propostas, como a classificação semântica proposta por Allerton (1987), que contém seis subcategorias (seres humanos; navios, veículos e máquinas; lugares geográficos; organizações sociais; publicações e obras de arte e línguas e dialetos); bem uma mais atual elaborada por Van Langendonck (2007), o qual propõe a distinção entre nomes próprios prototípicos (nome pessoais, nomes de animais, nomes de furacões, nomes de lugares, nomes de objetos astronômicos, nomes de construções e embarcações e nomes de organizações e associações) e nomes não prototípicos divididos em contáveis (nomes temporais, nomes de obra de arte, livros, jornais, filmes, etc., nomes de instituições conectadas com edifícios, nomes comerciais e de marca, nomes de moedas, nomes de números e letras) e não contáveis (nomes de idiomas, nomes de cores e nomes de doenças).

Amaral e Seide (2020) observam que, dentre todas as tipologias apresentadas para os nomes próprios, os nomes de lugares (topônimos) e os nomes de pessoas (antropônimos) constituem as categorias mais importantes. Os autores, a partir de critérios linguísticos e sociais elaboraram outra proposta tipológica para os nomes próprios dividida em seis grandes categorias: antropônimos (nomes de pessoas), topônimos (nomes de lugares), organizações sociais públicas e privadas, produtos da atividade humana, animais individualizados e eventos individualizado. No que tange aos antropônimos ${ }^{4}$, foco deste trabalho, os autores subdividem a categoria em: nome civil, nome não civil, nome do mundo fictício, nome do mundo religioso e nome do mundo mitológico.

\footnotetext{
${ }^{4}$ Por questões de espaço e escopo do artigo não apresentaremos as demais subcategorias da proposta tipológica feita por Amaral e Seide (2020), no entanto, é possível acessar a obra completa, gratuitamente, por meio do link: https://openaccess.blucher.com.br/article-details/11-21982. Acesso em: 15 out. 2021.
} 
Os nomes do mundo fictício, segundo Amaral e Seide (2020), podem ser baseados na norma linguística vigente à época da elaboração da obra literária, e baseados no significado etimológico dos nomes fictícios.

\section{Estudos Antroponomásticos na Libras}

Em diferentes comunidades surdas espalhadas pelo mundo é comum a atribuição de um sinal de nome ${ }^{5}$ às pessoas que pertencem a estas comunidades, como no caso dos próprios surdos, professores e intérpretes (PAALES, 2011) bem como às pessoas que necessitam ser referenciadas como autores/pesquisadores, artistas, gestores, políticos, dentre outros (RECH; SELL, 2020).

Na Língua Brasileira de Sinais, a primeira pesquisa voltada aos antropônimos na Libras foi realizada por Souza e Gediel (2017) que, por meio de uma pesquisa de cunho etnográfico com surdos residentes em uma cidade da Zona da Mata Mineira, mapearam o que denominaram de sinais próprios e verificaram suas principais características fonológicas. As autoras identificaram os sinais próprios como um "marcador identitário e cultural desses sujeitos [surdos], pois é a forma como eles se reconhecem e são reconhecidos pelos demais sinalizantes" (SOUZA; GEDIEL, 2017, p. 183).

Barros (2018) realizou entrevistas com 113 alunos e professores da Universidade Federal de Goias (UFG) e, a partir dos sinais de nomes coletados e outros que a própria autora conhecia, identificou, descreveu e nomeou quatro taxes: Empréstimos da Língua Oral (ELO) abrange os sinais de nome motivados pela língua oral; Aspectos físicos (AF) - sinais de nome motivados pela aparência física do portador; Aspecto Comportamental (AC) - sinais de nome motivados pelo estado de humor, ou habilidades cognitivas ou por alguma característica referente ao comportamento do nomeado; e, Aspecto Social (AS), que compreende os sinais de nome que foram motivados por profissões ou algum acontecimento marcante. Cabe observar que cada taxe apresenta outras subtaxes. A partir do corpus analisado a autora identificou maior incidência de sinais motivados por empréstimos da língua oral combinados com aspectos físicos do referente.

Rech e Sell (2020) analisaram a atribuição de sinais de nome de 61 autores/pesquisadores dispostos no Manuário Acadêmico Escolar elaborado pelo INES a partir da proposta de taxonomia elaborada por Barros (2018). As autoras identificaram que a maioria

\footnotetext{
${ }^{5}$ Signo linguístico que identifica e referencia um indivíduo em particular.
} 
dos sinais de nome foram motivados por algum aspecto físico do portador e acrescentam que a grande parte dos sinais pode ser classificada de acordo com as taxes, no entanto,

\footnotetext{
[...] alguns sinais de nome apresentaram características peculiares que ainda carecem de estudo aprofundado, como no caso de sinais de nome que parecem apresentar Classificadores em sua formação, ou ainda aqueles que apresentam fenômenos envolvendo percepção imagética e, ainda, aqueles que sugerem algum processo metafórico. (RECH; SELL, 2020, p. 80)
}

No mesmo ano, Rech (2020) analisou 92 sinais de nome de personagens bíblicas encontradas no manual de sinais bíblicos O Clamor do Silêncio, publicado pela Junta de Missões Nacionais da Convenção Batista Brasileira, no ano de 1991. O objetivo do trabalho foi evidenciar como os nomes das personagens bíblicas foi traduzido da Língua Portuguesa para a Língua Brasileira de Sinais. A autora identificou que a maioria dos sinais de nomes atribuídos às personagens bíblicas foi motivado pelo nome em português de forma isolada ou combinada com algum acontecimento que marcou a biografia do nomeado. Rech (2020) sugere que a influência da língua oral pode estar atrelada ao momento histórico da Libras, pois à época ainda não era reconhecida legalmente. Por fim, a pesquisa constatou que apenas um sinal de nome foi criado tendo como motivação algum aspecto físico do portador, o que vai na contramão do que foi identificado por Barros (2018) e Rech e Sell (2020). Segundo a autora, "Uma possível justificativa para essa diferença pode estar relacionada à ausência de imagens ou de descrições da aparência das referidas personagens" (RECH, 2020, p. 420).

Os estudos apresentados indicam que, nos últimos anos, novas pesquisas na área das pesquisas onomásticas nas línguas de sinais estão despontando. No entanto, ainda são embrionárias e introdutórias carecendo de mais aprofundamentos. Este trabalho trará uma nova contribuição no sentido de dialogar com os Estudos da Tradução.

\section{Tradução de nomes próprios, Literatura infantil e Língua de sinais}

O contato entre línguas e culturas diferentes, desde os tempos mais remotos, insurgem barreiras linguísticas e nos permitem inferir que práticas de tradução/interpretação sempre existiram. Como em outras áreas, os profissionais tradutores e intérpretes começam a se especializar, tornam-se profissionais. Os fazeres da tradução/interpretação, no correr da história, vão se consolidando e se constituindo com competências que podem ser ensinadas e aprendidas e passam a constituir o campo disciplinar denominado Estudos da Tradução (VASCONCELLOS, 1996). 
Quanto à tradução de nomes próprios, Nord (2003) adverte a existência de um imaginário coletivo em que os nomes próprios não seriam traduzidos. No entanto, segundo a autora, basta olhar os trabalhos que foram versados de uma língua para outra para que nos deparemos com várias estratégias como: a não tradução, a não-tradução que conduz a uma pronúncia diferente na língua-alvo, a transcrição ou transliteração de alfabetos não latinos, a adaptação fonológica para a língua-alvo, a adaptação cultural, a substituição, dentre outras. Para a autora, a partir da compreensão de tradução como um processo de transferência linguística e cultural, os nomes próprios podem ser traduzidos.

Nord (2013) aponta que os nomes próprios são monorreferenciais, ou seja, fazem referência direta a um único ser, mas jamais são monofuncionais, destacando que a principal função é identificar um referente em particular. Na sequência, a autora destaca, seguindo Strawson, que muitas vezes os nomes próprios são compreendidos como vazios de significado descritivo (STRAWSON, 1971, p. 23 apud NORD, 2003, p. 183) mas defende que, no mundo real os nomes próprios podem não ser descritivos, mas são informativos, ou seja, caso alguém tenha conhecimento da cultura em questão, é possível inferir se o nome próprio é masculino ou feminino, se é um nome de um animal de estimação, um nome de lugar etc. Todos esses conhecimentos, segundo Seide (2021), compreendem a competência ou conhecimento onomástico do falante, ou seja, a competência ou conhecimento onomástico do falante diz respeito ao "conhecimento sobre as características linguísticas dos nomes próprios em sua língua materna e sobre como eles são usados na comunidade linguística à qual ele pertence" (SEIDE, 2021, p. 60).

Especificamente no caso dos nomes próprios fictícios, ou antropônimos ficcionais, Nord (2003) esclarece que, em algumas culturas, esses nomes podem servir como "marcadores de cultura", ou seja, indicam implicitamente a cultura a qual o personagem pertence. Como exemplo, em uma obra literária em que o enredo ocorreu na Alemanha, a apresentação de uma personagem com o nome Joséphine, nos faz deduzir que ela seja de origem francesa. A autora chama a atenção também para o fato de que as ilustrações encontradas nas histórias traduzidas podem trazer elementos que limitam ou inviabilizam as adaptações nas traduções de nomes próprios, já que o tradutor precisa lidar também com a mensagem da imagem vinculada ao personagem.

O fato de lidar com imagens na tradução de histórias pode apresentar impacto também nas traduções entre línguas de modalidades diferentes. Em relação a esse processo de tradução, Quadros e Segala (2015) discutem a tradução intermodal, isto é, entre línguas de modalidades diferentes, salientando que no caso de tradução do português escrito para a Libras há três 
aspectos envolvidos que influenciam o processo tradutório. $\mathrm{O}$ primeiro deles diz respeito ao fato de que esse processo acarreta a sobreposição de elementos tradutórios e interpretativos, uma vez que o tradutor, mesmo tendo tempo para organizar o processo tradutório, o momento da filmagem da tradução em vídeo se apresenta como um processo de interpretação também, já que lida com a "oralidade" da língua de sinais. Sendo assim, havendo necessidade de editar a tradução, a probabilidade de recortes no material já filmado é menor, a menos que a filmagem seja refeita, o que nos leva novamente para a condição da interpretação.

O segundo aspecto levantado pelos autores que também é inerente às características da tradução e da interpretação trata da visibilidade do tradutor, que aparece visualmente nos vídeos, dando a eles autoria da tradução e de certa forma apagando a autoria do autor da língua fonte. Por fim, o terceiro aspecto da tradução intermodal e que também se relaciona às características da tradução e da interpretação envolvem a atuação performática do tradutor no momento da tradução. Conforme Quadros e Segala (2015),

[...] o tradutor expõe o seu corpo diante da câmera e produz um texto em sinais que exigirá uma espécie de "performance" em sinais. Essa performance em sinais é organizada discursivamente usando recursos linguísticos (o texto em si na Libras) e paralinguísticos típicos de textos na modalidade visual-espacial (por exemplo, uso de descrições imagéticas, antropomorfismo, incorporação e uso do espaço de sinalização) (QUADROS; SEGALA, 2015, p. 362).

Como se pode notar, a tradução intermodal apresenta características específicas uma vez que lida com línguas em modalidades distintas, com caraterísticas linguísticas diferentes. Há que se levar em consideração também o aspecto da estrutura visual e espacial da Libras no ato tradutório e de seus recursos visuais como é o caso da descrição imagética, própria das línguas de sinais. Além disso, a tradução para a língua de sinais vai envolver aspectos próprios da tradução, como o tempo de análise e planejamento da versão na língua alvo, bem como aspectos da interpretação, já que o produto da tradução acontecerá na “oralidade” da língua de sinais.

Quanto à tradução de nomes da literatura infantil, Fernandes (2006) propõe, a partir de informações extraídas do PEPCOCFL - Corpus Paralelo Português-inglês de Literatura Infantil de Fantasia $^{6}$ - dez procedimentos para a tradução de nomes ficcionais. Seus estudos baseiamse na ideia original de Hermans (1988 apud FERNANDES, 2006), segundo a qual os nomes podem ser divididos em: Nomes convencionais (sem carga semântica): desmotivados para

\footnotetext{
${ }^{6}$ Segundo o autor, “o PECOCFL é um corpus paralelo eletrônico bilíngue composto por 24 livros de fantasia (12 originais +12 traduções) extraídos de quatro séries de fantasia inglesa traduzidas para o português brasileiro no período de 2000 a 2003 (FERNANDES, 2006, p. 50).
} 
tradução, e Nomes semanticamente carregados (loaded names): motivados para tradução. O quadro a seguir sumariza os dez procedimentos apresentados por Fernandes:

Quadro 1 - Procedimentos para tradução de nomes ficcionais

\begin{tabular}{|c|c|}
\hline Procedimento & Explicação \\
\hline $\begin{array}{l}\text { Nomes traduzidos } \\
\text { (Rendition) }\end{array}$ & $\begin{array}{l}\text { Este procedimento é utilizado quando um nome em um texto fonte está } \\
\text { emaranhado dessa língua, adquirindo assim "significado" a ser processado na } \\
\text { língua alvo (HERMANS, } 1988 \text { apud FERNANDES, 2006). }\end{array}$ \\
\hline Cópia & $\begin{array}{l}\text { Os nomes são reproduzidos no texto alvo exatamente como aparecem no texto } \\
\text { fonte, sem qualquer alteração. }\end{array}$ \\
\hline Transcrição & $\begin{array}{l}\text { Ocorre quando um nome é transliterado ou, de alguma forma, adaptado ao } \\
\text { nível da morfologia, fonologia, gramática etc. }\end{array}$ \\
\hline Substituição & $\begin{array}{l}\text { O nome do texto alvo e o nome do texto fonte existem em seus respectivos } \\
\text { mundos referenciais, no entanto, não estão relacionados em termos de forma } \\
\text { e/ou significado semântico. }\end{array}$ \\
\hline Recriação & $\begin{array}{l}\text { Consiste na recriação de um nome inventado no texto fonte no texto alvo, com } \\
\text { o objetivo de reproduzir efeitos parecidos do referente recém-criado na } \\
\text { cultura alvo. }\end{array}$ \\
\hline Supressão & Envolve a remoção total ou parcial no texto fonte. \\
\hline Adição & $\begin{array}{l}\text { Procedimento no qual informações extras são adicionadas ao nome original, } \\
\text { tornando-o mais compreensível, ou atraente, na cultura alvo. }\end{array}$ \\
\hline Transposição & $\begin{array}{l}\text { Consiste na substituição de uma classe de palavra por outra sem alterar o } \\
\text { significado do nome presente no texto fonte. }\end{array}$ \\
\hline $\begin{array}{l}\text { Substituição } \\
\text { fonológica }\end{array}$ & $\begin{array}{l}\text { Este é um procedimento no qual um nome no texto alvo tenta imitar } \\
\text { características fonológicas ou ortográficas de um nome no texto fonte. }\end{array}$ \\
\hline Convencionalidade & $\begin{array}{l}\text { Este procedimento ocorre quando um nome no texto fonte é } \\
\text { convencionalmente aceito como tradução de um nome específico (exônimos). }\end{array}$ \\
\hline
\end{tabular}

Fonte: adaptado de Fernandes (2006).

Vale ressaltar que os procedimentos apresentados por Fernandes (2006) se baseiam em traduções entre línguas na mesma modalidade. Nesse sentido, a análise dos dados apresentada na próxima seção parte desse referencial teórico e o problematiza, já que os dados coletados se referem à tradução intermodal. 


\section{Percurso metodológico e análise dos dados}

Para analisar as escolhas tradutórias dos nomes das personagens das histórias infantis da Língua Portuguesa para a Libras escolhemos 8 vídeos produzidos pelo INES, em parceria com o Ministério da Educação e Cultura (MEC) no ano de 2005, os quais estão disponíveis na internet. As histórias selecionadas foram: Chapeuzinho Vermelho ${ }^{7}$, Patinho Feio ${ }^{8}$, Rapunzel ${ }^{9}$, Cinderela $^{10}$, Branca de Neve e os Sete Anões ${ }^{11}$, João e Maria ${ }^{12}$, A Bela Adormecida ${ }^{13}$ e Os Três $\operatorname{Ursos}^{14}$.

A opção pelos vídeos mencionados está relacionada ao fato de o Instituto ser uma referência nacional na produção de materiais didáticos e pedagógicos para surdos, além da possibilidade da percepção de como os surdos fazem as escolhas tradutórias das personagens infantis, uma vez que as histórias foram traduzidas por professores surdos contratados pelo INES. Vale lembrar que daquela época para cá pode ter havido retraduções, as quais não fazem parte do escopo dessa pesquisa, pois não estão disponíveis no acervo on-line do INES.

Como esta pesquisa buscou verificar as traduções de antropônimos ficcionais, selecionamos apenas as personagens das histórias que receberam um sinal de nome específico, desconsiderando aquelas personagens que foram referenciadas por meio de sinais que denotavam sinais genéricos. Neste sentido, foram descartadas para a presente análise aquelas personagens que são referenciadas apenas por alguma profissão - como o caso do caçador da história da Chapeuzinho Vermelho, ou pelo grau parentesco - como o caso das avós, mães, madrastas, pai etc. Tendo em vista tal recorte, foram selecionados um total 16 personagens com sinais de nome específicos.

Com o objetivo de encontrar os sinais das personagens assistimos todos os vídeos e identificamos que 4 histórias - Chapeuzinho Vermelho, Rapunzel, Patinho Feio, Cinderela apresentam seus personagens principais logo na apresentação, o que proporcionou uma fácil localização dos sinais. A introdução da história da Branca de Neve apresentou as características de cada personagem e apresentou os sinais de nome da personagem que leva o nome da história e dos sete anões: Mestre, Feliz, Atchin, Dengoso, Soneca, Zangado e Dunga. No caso de João e Maria e da Bela Adormecida os sinais de nomes só apareceram no decorrer da história.

\footnotetext{
${ }^{7}$ Disponível em: https://youtu.be/JuCVU9rGUa8. Acesso em: 25 jun. 2021.

${ }^{8}$ Disponível em: https://youtu.be/owLpgKy8zbw. Acesso em: 25 jun. 2021.

${ }^{9}$ Disponível em: https://youtu.be/2TlqCHIvMh0. Acesso em: 25 jun. 2021.

${ }^{10}$ Disponível em: https://youtu.be/RimMKqUVXPM. Acesso em: 25 jun. 2021.

${ }^{11}$ Disponível em: http://tvines.org.br/?p=5769. Acesso em: 25 jun. 2021.

${ }^{12}$ Disponível em: https://youtu.be/rfpHF_94quo. Acesso em: 25 jun. 2021.

${ }^{13}$ Disponível em: https://youtu.be/AZMV9kaQtyA. Acesso em: 25 jun. 2021.

${ }^{14}$ Disponível em: https://youtu.be/XofXq-97DlQ. Acesso em: 25 jun. 2021.
} 
Sendo assim, dedicamo-nos a identificar as traduções dos nomes das personagens realizadas pelos tradutores surdos tendo como base os dez procedimentos identificados por Fernandes (2006): nomes traduzidos (rendition), cópia, transcrição, substituição, recriação, supressão, adição, transposição, substituição fonológica e convencionalidade. Para facilitar a visualização dos dados, elaboramos um quadro contendo três colunas: nome da personagem, imagem do sinal e o procedimento de tradução adotado. Após análise inicial identificamos que apenas seis procedimentos foram adotados e alguns foram combinados conforme disposto na Tabela 1, os quais são analisados na sequência.

Tabela 1 - Quantidade de ocorrências por procedimento

\begin{tabular}{l|c}
\hline \multicolumn{1}{c|}{ Procedimento } & Quantidade de ocorrências \\
\hline Recriação & 6 \\
\hline Rendition & 5 \\
\hline Rendition + Supressão & 1 \\
\hline Rendition + Adição & 2 \\
\hline Rendition + Supressão + Adição & 1 \\
\hline Transposição + Adição & 1 \\
\hline Total & 16 \\
\hline
\end{tabular}

Fonte: elaboração própria.

O procedimento adotado com o maior número de ocorrências foi o que Fernandes (2006) chamou de rendition, quer seja na forma isolada, quer seja na forma combinada. Como recurso único este procedimento foi realizado na tradução para Libras das seguintes personagens: Atchin, Soneca, Zangado, Patinho Feio e Mestre as quais foram nomeadas pelos sinais ESPIRRAR, SONO,BRAV@,PAT@ FEI@ e INTELIGENTE ${ }^{15}$ respectivamente. Cabe observar que, segundo Fernandes (2006), o procedimento rendition é usado quando o nome é transparente ou semanticamente motivado, mas, tendo em vista a língua alvo, pode haver alguma adaptação. Isso parece ocorrer com a personagem Mestre traduzido na Libras pelo lexema INTELIGENTE. Uma hipótese para tal escolha pode ser explicado devido ao fato de, na Libras, não haver um sinal equivalente ${ }^{16}$ para mestre, no sentido requerido pelo contexto, o que pode ter levado os tradutores a escolher um termo aproximado que tem consonância com as características da personagem.

15 Para anotar os sinais de Libras utilizou-se o sistema de transcrição por glosas, que representa, em letras maiúsculas, o significado aproximado do sinal em Libras com vocábulos da língua portuguesa. Deve se levar em conta que sinais isolados da Libras podem gerar dúvidas quanto à classe gramatical a que pertencem. Esse procedimento de transcrição é comum e usual nos estudos referentes às línguas de sinais.

${ }^{16}$ Em consulta ao Dicionário da Língua de Sinais do Brasil (CAPOVILLA et al. 2019), na entrada "mestre" é apresentado o sinal de PROFESSOR. 
O nome Branca de Neve, por sua vez, foi traduzido por meio de três procedimentos: rendition, supressão e adição. $\mathrm{O}$ sinal de nome cunhado na Libras salientou o formato chanel do cabelo da personagem acrescido do sinal BRANCO e suprimiu a palavra "neve”. Nesse aspecto pode-se observar a influência da ilustração/imagem apontada por Nord (2003) na escolha tradutória, em que o tradutor leva em conta a imagem conhecida da personagem Branca de Neve para selecionar uma de suas características físicas, no caso em questão o corte de cabelo típico, na construção de seu sinal de nome.

Ainda em relação a esse aspecto, vale lembrar que estudos sobre a Antroponomástica na Libras, anteriormente mencionados, apontam para a produtividade da criação de sinais de nome motivados por aspectos físicos dos seres nomeados (BARROS, 2018; RECH; SELL, 2020).

A personagem Feliz, que fazem parte da história da Branca de Neve, foi traduzido como PRAZER/GOSTAR+FELIZ utilizando dois procedimentos: rendition e adição. Em relação ao rendition, segue o que já foi explicado anteriormente: o nome é semanticamente motivado e tem um correspondente na língua alvo, o que explica o sinal FELIZ. O acréscimo diz respeito ao sinal PRAZER/GOSTAR, que pode servir como um intensificador, o que mereceria uma investigação mais aprofundada, por exemplo, com entrevistas realizadas com os tradutores surdos a fim de investigar a motivação para a construção do referido sinal. O mesmo procedimento acontece no sinal de Chapeuzinho Vermelho, traduzido como CHAPÉU+LAÇO+ VERMELHO, em que há a adição do sinal de LAÇO.

Já o sinal atribuído a Cachinhos Dourados foi traduzido utilizando o procedimento rendition e supressão, formando, na Libras, o sinal CL-CABELO-CACHEADO, sem fazer referência à cor do cabelo. Nesse caso, parece haver a tradução baseada na descrição imagética, caraterística típica da tradução intermodal apontada por Quadros e Segala (2015).

O procedimento recriação foi utilizado na tradução dos sinais de nome para João (Sinal na testa provavelmente ligado ao cabelo) e Maria (Sinal ao lado do rosto, provavelmente ligado ao cabelo), Bela Adormecida (Sinal lembrando o cabelo), Rapunzel (Sinal lembrando tranças), Cinderela (Sinal na cabeça, provavelmente ligado a uma tiara) e Dunga (Configuração de mão lembrando orelhas grandes). No caso dos sinais de nome recriados na Libras é possível perceber novamente a visualidade como ponto de partida na criação de antropônimos ficcionais, em que a maioria parte de aspectos físicos das personagens. O sinal criado para Cinderela difere dos demais por apresentar no lugar de uma característica física, um acessório na formação do sinal.

Por fim, para a tradução de Dengoso (CARINHO + CL de cílios) utilizou-se o procedimento de Transposição, em que o substantivo CARINHO é utilizado para figurar como 
sinal de nome com adição de uma característica física da personagem, no caso os cílios, provavelmente baseada na ilustração/imagem desta constante nos livros/filmes da história da Branca de Neve com os quais temos contato. Mais uma vez aqui evidencia-se a influência de imagens/ilustrações apontada por Nord (2003) na tradução de nomes próprios da literatura infantil.

Cabe observar que embora apenas alguns dos nomes das personagens na Língua Portuguesa sejam nomes descritivos, ou seja, existiu uma intenção de salientar algum aspecto físico ou comportamental do referente nomeado, quando os nomes foram traduzidos para a Libras, todas as traduções apresentaram algum aspecto descritivo do referente. Essa descrição física está relacionada com a visualidade das línguas de sinais, na qual a imagem exerce um papel importante na criação dos sinais de nome das personagens (ALBRES, 2016).

\section{Considerações finais}

Esse estudo se propôs a discutir a tradução de nomes de personagens de histórias clássicas da literatura infantil para a Libras a partir dos Estudos Antroponomásticos e dos procedimentos de tradução conforme Fernandes (2006). Pode-se observar que, em se tratando de tradução intermodal (QUADROS; SEGALA, 2015), o processo tradutório ora analisado apresentou influência da modalidade da língua alvo, em que aspectos pertinentes à interpretação se fazem evidentes, bem como aqueles ligados à estrutura espaço visual das línguas de sinais, como é o caso do uso de classificadores na formação dos antropônimos ficcionais.

Quanto aos Estudos Antroponomásticos, evidenciou-se com as discussões sobre os dados encontrados que a tradução de antropônimos ficcionais para a Libras, mesmo se utilizando de procedimentos diferentes, apresenta traços da criação de sinais de nomes da cultura surda brasileira, em que frequentemente aspectos físicos do ser nomeado são utilizados para a criação total ou parcial de sinais de nome, com destaque para a experiência visual dos surdos (Cf. BARROS, 2018; RECH; SELL, 2020).

Da análise realizada nos dados obtidos, evidenciou-se ainda que o procedimento rendition foi o mais utilizado, tanto isoladamente como em combinação com outros procedimentos. Além disso, parte dos procedimentos apontados por Fernandes (2006) não foram encontrados no corpus analisado, o que aparentemente parece ser coerente, uma vez que foram descritos a partir da comparação tradutória de duas línguas orais: inglês e português.

Há que se investigar, em trabalhos futuros, como se comportam tais procedimentos tradutórios em traduções intermodais, tendo em vista as especificidades envolvidas nesse processo, conforme apontam Quadros e Segala (2015) e, a partir de tais estudos, descrever 
outros procedimentos que envolvam uma língua sinalizada e suas caraterísticas específicas. Esperamos, com esse estudo, abrir novas perspectivas nos estudos onomásticos em interface com os estudos da tradução e as línguas de sinais.

\section{Referências}

ALLERTON, D. J. The linguistic and sociolinguistic status of proper names. Journal of Pragmatics, North-Holland, v. 11, n. 1, p. 61-92, 1987.

ALVES, N. de A. A construção de sinais-nome para personagens na tradução de literatura infanto-juvenil para Libras. Belas Infiéis, Brasília, v. 5, n. 1, p. 73-92, 2016.

AMARAL, E. T. R.; SEIDE, M. S. Nomes próprios de pessoa: introdução à antroponímia brasileira. São Paulo: Blucher, 2020.

BARROS, M. E. Taxonomia Antroponímica nas Línguas de Sinais: a motivação dos Sinaisnomes. RE-UNIR, Rondônia, v. 5, n. 2, p. 40-62, 2018.

CAPOVILLA, F C. et al. Dicionário da Língua de Sinais do Brasil: a Libras em suas mãos. São Paulo: EDUSP, 2019.

FERNANDES, L. Translation of Names in Children's Fantasy Literature: Bringing the Young Reader into Play. New Voices in Translations Studies, v. 2, p. 44-57, 2006.

NORD, C. Proper Names in Translation for Children: Alice in Wonderland as a Case Point. Meta, Montreal, v. 48, n. 1-2, p. 182-196, maio 2003.

PAALES, L. Name signs for hearing people. Folklore, Estônia, v. 47, p. 43-76, 2011.

QUADROS, R. M., SEGALA, R. R. Tradução Intermodal, intersemiótica e interlinguística de textos escritos em português para a Libras oral. Cadernos de Tradução, Florianópolis, v. 35, n. especial 2, p. 354-386, 2015.

SEABRA, M. C. T. C. Referência e Onomástica. In: MAGALHÃES, J. S. de; TRAVAGLIA, L. C. (Orgs.). Múltiplas perspectivas em linguística: Anais do XI Simpósio Nacional e I Simpósio Internacional de Letras e Linguística (XI SILEL). Uberlândia: ILEEL, 2006. p. 1953-1960.

RECH, G.C.; SELL, F.S.F; SEIDE, M.S. A nomeação de pessoas em diferentes comunidades surdas. Revista Investigações, Recife, v. 33, n. 2, p. 1-24, 2020.

RECH, G. A Tradução dos nomes das personagens bíblicas para a Língua Brasileira de Sinais: analisando o manual O Clamor do Silêncio. Revista Linguística, Rio de Janeiro, v. 16, n. 3, p. 404-424, 2020.

SEIDE, M. S. Métodos de pesquisa em Antroponomástica. Domínios da Linguagem, Uberlândia, v. 10, n. 3, p. 1146-1171, 2016. 
SEIDE, M. S. Prenomes cristãos: constituição, etimologia, motivação para a escolha antroponímica e conhecimento onomástico. Revista Estudos da Linguagem, Belo Horizonte, v. 29, n. 1, p. 49-76, 2021.

SILVA, B. Z. da. As traduções dos nomes próprios nas histórias em quadrinhos: um estudo de caso das tiras de Mafalda, de Quino. TradTerm, São Paulo, v. 27, p. 155-179, 2016.

SOUZA, I. L.; GEDIEL, A. L. Os sinais dos surdos: uma análise a partir de uma perspectiva cultural. Trabalhos em Linguística Aplicada, Campinas, v. 56, n. 1, p. 163-185, 2017.

VAN LANGENDONCK, W. Theory and typology of proper names. Berlin: Walter de Gruyter, 2007.

VASCONCELLOS, M. L. Tradução e Interpretação de Línguas de Sinais (TILS) na PósGraduação: a afiliação ao campo disciplinar "Estudos da Tradução". Cadernos de Tradução, Florianópolis, v. 2, n. 26, p. 119-143, 2010.

\section{Sobre as autoras}

Gabriele Cristine Rech (Orcid iD: https://orcid.org/0000-0003-2470-3416)

Doutoranda no Programa de Pós-Graduação em Letras da Universidade Estadual do Oeste do Paraná (Unioeste); mestra em Linguística pela Universidade Federal de Santa Catarina (UFSC); especialista em Educação Especial - Área da Surdez e Libras pela Univale; graduada em Pedagogia pela Universidade Estadual de Ponta Grossa (UEPG) e em Teologia pela Faculdade Teológica Sul Americana (FTSA). É professora efetiva da Universidade Estadual do Mato Grosso do Sul (UEMS).

Fabíola Sucupira Ferreira Sell (Orcid iD: https://orcid.org/0000-0002-2315-7073) Doutora e mestra em Linguística pela Universidade Federal de Santa Catarina (UFSC); licenciada em Letras-Alemão e bacharela em Letras-Libras pela mesma instituição. É professora do Centro de Ciências Tecnológicas e do Programa de Pós-Graduação em Ensino de Ciências, Matemática e Tecnologias da Universidade do Estado de Santa Catarina (UDESC).

Recebido em junho de 2021.

Aprovado em outubro de 2021. 